Psychological Medicine, 1988, 18, 807-812

Printed in Great Britain

\title{
EDITORIAL
}

\section{The outcome of anorexia nervosa: a reappraisal ${ }^{1}$}

In 1980, Hsu reviewed 16 major studies on the outcome of anorexia nervosa published between 1954 and 1979 and came to the conclusion proposed earlier by Russell (1970) that outcome in a given series depends largely on two factors: (1) the selection of cases that constitute the series, and (2) the criteria and method with which outcome is assessed. Overall he found that $75 \%$ of patients had improved at follow-up four to eight years later, and that the mortality for the illness was low (less than $5 \%$ in the more recent studies). A subsequent review of 45 studies by Steinhausen \& Glenville (1983) did not seem to contradict these claims.

This rather optimistic view is not supported by the findings of two recent long-term (over 20 years) outcome studies. Theander (1985) refollowed the patients he had earlier reported on in 1970 , and found a mortality of $18 \%$ at the 24 year follow-up. Russell (1987, personal communication) also refollowed patients that he and Morgan reported on in 1975 and found essentially the same results : a mortality of $15 \%$ at 20 years. Furthermore, the debate surrounding the issue that anorexia nervosa is a variant of affective illness (Cantwell et al. 1977) continues unabated. Finally, several studies with more robust methodology have been published in the last few years. It is time for a reappraisal of the outcome of anorexia nervosa.

\section{RECENT INTERMEDIATE TERM OUTCOME STUDIES}

In the last few years three studies using essentially the same methodology as Morgan \& Russell (1975) and Hsu et al. (1979) have been published (see Table 1). They shared the following characteristics:

1. All the studies used explicitly stated diagnostic criteria such that atypical cases were excluded. Morgan \&. Russell (1975) and Morgan et al. (1983) used Russell's criteria (1970); Hsu et al. (1979) and Burns \& Crisp, (1984) used Crisp's criteria (1977); while Hall et al. (1984) used the Feighner criteria (Feighner et al. 1972). Despite these differences, from the demographic and weight characteristics reported we can conclude that all the patients in the five series have anorexia nervosa with similar severity.

2. All the studies followed the patients for at least four years. Morgan \& Russell (1975) dated the duration of their follow-up from hospital discharge; Hsu et al. (1979), Morgan et al. (1983), and Burns \& Crisp, (1984) dated their studies from time of presentation; and Hall et al. (1984) from the onset of illness. Despite these differences the duration from onset of illness for all the series is probably similar, although the series of Burns \& Crisp (1984) and Hall et al. (1984) may have contained more patients with a shorter duration of illness. The onset of illness is sometimes hard to define, depending on whether it is dated from the onset of dieting, or major weight loss, or amenorrhea, and since many patients receive only out-patient treatment, and because discharge from in-patient care does not mean treatment termination, it may be preferable in future studies to date the follow-up duration from the time of presentation to the investigators' clinic. All the five studies are best described as intermediate term outcome studies, a point that we will return to later.

3. All the studies had a low failure-to-trace rate, and a high direct interview rate. Obviously, a high failure-to-trace rate and indirect methods of follow-up (including not weighing the patient) are likely to bias the findings. The five studies have a failure-to-trace rate of less than $5 \%$ and a direct interview rate in excess of $70 \%$.

4. All used multiple and well defined outcome criteria. Confusion can easily arise if global outcome scores are undefined. For instance, Cantwell et al. (1977) rated only one patient (less than

' Dr L. K. G. Hsu, Department of Psychiatry, Division of Child and Adolescent Psychiatry, University of Pittsburgh, Western Psychiatric Institute and Clinic, 3811, O'Hara Street, Pittsburgh, PA 15213-2593, USA. 
Table 1. Mortality, weight and menstruation at follow-up

\begin{tabular}{|c|c|c|c|c|c|c|}
\hline & \multirow[b]{2}{*}{ Mortality (\%) } & \multicolumn{3}{|c|}{ Weight (\%) } & \multicolumn{2}{|c|}{ Menstrual outcome (\%) } \\
\hline & & Normal & Over & Very low & Regular & Amenorrhea \\
\hline Morgan \& Russell (1975) & 5 & 55 & 5 & 20 & 47 & 39 \\
\hline Hsu et al. (1979) & 2 & 62 & 2 & 15 & 51 & 28 \\
\hline Morgan et al. (1983) & 1 & $\geqslant 58$ & - & - & $\geqslant 58$ & $\geqslant 19$ \\
\hline Hall et al. (1984) & 1 & 50 & 10 & 14 & \multirow{2}{*}{\multicolumn{2}{|c|}{ Not applicable }} \\
\hline Burns \& Crisp (1984) & 0 & 52 & 4 & 11 & & \\
\hline
\end{tabular}

Table 2. Outcome (per cent of patients) according to Morgan's outcome category

\begin{tabular}{lccccc}
\hline & Good & Intermediate & Poor & Death & Untraced \\
\hline Morgan \& Russell (1975) & 39 & 27 & 29 & 5 & 0 \\
Hsu et al. (1979) & 45 & 30 & 20 & 2 & 3 \\
Morgan et al. (1983) & 58 & 19 & 19 & 1 & 3 \\
Hall et al. (1984) & 36 & 36 & 24 & 2 & 2 \\
Burns \& Crisp (1984) & 44 & 26 & 30 & 0 & 0 \\
$\quad$ Mean & 44 & 28 & 24 & 2 & 2 \\
\hline
\end{tabular}

$5 \%$ ) as having possible anorexia nervosa at follow-up but elsewhere Sturzenburger et al. (1977) reported that body weight outcome was poor in $20 \%$ of the patients. Such confusion renders interpretation of findings difficult. All the five studies used Morgan \& Russell's outcome criteria and thus allow for direct comparison of their findings.

However, these studies still have methodological flaws. None use a standardized structured or semi-structured interview for the assessment of the patient's mental state at follow-up. The rating scales used were largely non-standardized. None of the studies addressed specifically the question of the relationship between anorexia nervosa and affective illness, or anorexia nervosa and bulimia nervosa; however, this shortcoming is understandable since interests in these issues are more recent. All the studies were based on patients referred to teaching hospitals and thus highly selected. All the studies had a relatively short follow-up duration. At the time of follow-up which occurred at four to 12 years after the onset of illness, the patients would have been in their late 20 s or early $30 \mathrm{~s}$, at which time the illness might not have run its full course. Finally, none of the studies expressed mortality in terms of standarized mortality ratio, thus making comparison of mortality rates between studies and with age and sex specific death-rates of the general population impossible.

Nevertheless, much has been learned from these recent studies regarding the outcome of anorexia nervosa and their findings will be discussed under topics of current interest.

\section{OVERALL OUTCOME}

Given their methodological similarities, it is perhaps not surprising that outcome in the five studies is very similar (Tables 1 and 2). Between $50 \%$ to $60 \%$ of patients were at normal weight, and $47 \%$ to $58 \%$ are having regular menses. Crude mortality rates varied from $0-5 \%$, while $11-20 \%$ of the patients were still markedly underweight at follow-up. It is perhaps remarkable that the outcome in males is essentially the same as that in females. Theander's earlier study (Theander, 1970), which used similar weight and menstrual status criteria, also found $51 \%$ at outcome to have a normal bodyweight and $66 \%$ to have regular menses.

\section{PROGNOSTIC INDICATORS}

Five factors were found by at least three of the studies to indicate poor outcome: longer duration of illness, lower minimum weight, pre-morbid personality and social difficulties, disturbed 
Table 3. Prognostic indicators (factors associated with poor outcome)

\begin{tabular}{|c|c|c|c|c|c|}
\hline & $\begin{array}{c}\text { Morgan \& } \\
\text { Russell (1975) }\end{array}$ & $\begin{array}{c}\text { Hsu } \\
\text { et al. (1979) }\end{array}$ & $\begin{array}{c}\text { Morgan } \\
\text { et al. (1983) }\end{array}$ & $\begin{array}{c}\text { Burns \& } \\
\text { Crisp (1984) }\end{array}$ & $\begin{array}{c}\text { Hall } \\
\text { et al. (1984) }\end{array}$ \\
\hline Longer duration of illness & $x$ & $x$ & $x$ & $x$ & - \\
\hline Lower minimum weight & $x$ & $x$ & - & $x$ & 一 \\
\hline Later age of onset & $x$ & $x$ & - & Possible & $\rightarrow$ \\
\hline Vomiting & - & $x$ & - & - & Possible \\
\hline Being married & - & $x$ & - & - & $x$ \\
\hline $\begin{array}{l}\text { Personality/social } \\
\text { difficulties }\end{array}$ & $x$ & $x$ & $x$ & Possible & - \\
\hline $\begin{array}{l}\text { Disturbed relationship } \\
\text { with family }\end{array}$ & $x$ & $x$ & $x$ & $x$ & - \\
\hline Previous treatment & $x$ & $x$ & - & $x$ & .. \\
\hline
\end{tabular}

relationship with family, and previous treatment (see Table 3). Theander (1970) found a later age of onset and vomiting to indicate poor outcome but his outcome measures were somewhat different. A longer duration of illness, lower weight and failed previous treatment are likely to be indexes of chronicity. Poor pre-morbid social adjustment also predicts poor outcome in schizophrenia (Cutting, 1986). However, none of the studies used standardized instruments to measure personality and social adjustment. Poor family interaction may breed chronicity through 'negative expressed emotion', a concept found useful in predicting relapse for both schizophrenia and depressive neurosis (Leff \& Vaughn, 1980). In a study of parental expressed emotion in 51 anorexics and bulimics, Szmukler et al. (1985) found parental critical comments to correlate with early treatment dropout; however, the investigators did not report on the association between negative expressed emotion and outcome of illness.

\section{MENTAL STATUS OUTCOME}

As already mentioned, one of the major shortcomings among the five studies is the failure to use a standardized interview for the assessment of mental state at outcome. Morgan \& Russell found $45 \%$ to show affective (usually depressive) symptoms and $23 \%$ obsessive symptoms. It is unclear how many would have qualified for a diagnosis of an actual disorder. Hsu et al. (1979) found $38 \%$ and $22 \%$ to report depressive and obsessive symptoms respectively, but again it is unclear how many would qualify as a 'case' of major depression or obsessive compulsive disorder. One patient was diagnosed as having bipolar disorder and three had schizophrenia. Morgan et al. (1983) found eight patients $(30 \%)$ to have marked psychiatric disturbances, of these three had alcohol or substance abuse, one severe obsessive neurosis, and four (15\%) unspecified. In addition, $22 \%$ had mixed phobic anxiety and depressive symptoms. Hall et al. (1984) used the DSM-III criteria for diagnosis and found $34 \%$ to have a dysthymic disorder, $6 \%$ major depression, $4 \%$ alcohol abuse and $2 \%$ each to have schizophrenia, bipolar disorder, and personality disorder. In total, it is clear that a significant proportion of patients (perhaps one-third) at follow-up have at least quite significant depressive symptoms and perhaps about $10 \%$ would qualify for major depression.

\section{DOES ANOREXIA NERVOSA CHANGE INTO BULIMIA NERVOSA?}

At presentation or admission, bulimia (undefined), occurred in between $38 \%$ (Hall et al. 1984) to $44 \%$ (Hsu et al. 1979; Burns \& Crisp, 1984), and vomiting occurred in between $27 \%$ (Morgan \& Russell, 1975) to $42 \%$ (Hsu et al. 1979). Since the frequency of such episodes were not described, it is unclear how many would also quality for a DSM-III-R diagnosis of bulimia nervosa, (i.e., more than two episodes per week). At follow-up Hsu et al. (1979) used a criteria of three episodes or more a week and found $19 \%$ to have bulimia and $21 \%$ vomiting; thus at least $19 \%$ of the patients would qualify for DSM-III-R bulimia nervosa. Burns \& Crisp (1984) found only $7 \%$ to have bulimia at 
follow-up and $10 \%$ vomiting, while Hall et al. (1984) reported that perhaps $38 \%$ of the patients had at least occasional bulimia and vomiting at follow-up. However, since the frequency of these episodes were not specified, it is unclear how many would fulfill DSM-III-R criteria for bulimia nervosa at follow-up.

Clearly, some patients lost their bulimia while others acquired it from presentation to follow-up. Hall et al. (1984) reported that six lost it while eight gained it. Hsu (1978), studying the first 50 of the 105 patients that he and Crisp reported later in 1979 , found $23(46 \%)$ initially to have bulimia at presentation (frequency of symptoms unknown), and of these seven ( $14 \%$, including the two who had died) on follow-up still had frequent (i.e. more than three times a week) bulimic and vomiting episodes: eight were no longer bulimic, while the other eight still binged and purged at least occasionally during the six months prior to follow-up. Thus, the majority of bulimic anorexics continued to have an eating disorder at follow-up, with two-thirds $(15 / 23)$ retaining their bulimia in varying degrees of severity. Only three $(13 \%)$ had changed from bulimic to restrictive anorexia nervosa, and five had recovered with no anorexia or bulimia nervosa. In contrast, of the 27 restrictive anorexics, seven $(7 / 27,26 \%)$ had developed bulimia of varying severity and in the process also gained weight (i.e. developed bulimia nervosa at normal weight), three (11\%) remained restrictive anorexics, and $17(63 \%)$ recovered and had no eating disorder. To summarize: $(l)$ with time, twice as many restrictive anorexics develop bulimia as do bulimic anorexics changing to restrictive anorexics, (2) most bulimic anorexics retain their bulimia; (3) restrictive anorexics who develop bulimia tend to gain weight (i.e. develop normal weight bulimia nervosa), while bulimic anorexics tended to remain bulimic anorexics; $(4)$ bulimia nervosa, normal weight or otherwise, is the commonist diagnosis after anorexia nervosa at follow-up; and (5) restrictive anorexics have a much better prognosis in terms of nutritional outcome.

\section{IS ANOREXIA NERVOSA A VARIANT OF AFFECTIVE ILLNESS?}

Russell (1970) has suggested that the constancy of the association of the various clinical features and the fact that the illness runs true-to-form are strong arguments for taking anorexia nervosa as a diagnostic entity. As already mentioned, none of these studies used a standardized instrument for the assessment of mental state at outcome, and only Hall et al. (1984) had used the DSM-III criteria to classify the diagnostic categories. Their findings suggest that dysthymic disorder is predominantly $(15 / 17)$ associated with poor or intermediate outcome. Only three patients qualified for major depressive disorder, two of them having a normal body weight. The other investigators all stated that depressive features were most commonly associated with those who were still anorexic. Using the Crown Crisp Experiential Index (CCEI) at presentation and follow-up Hsu \& Crisp (1980) found that depression scores decreased significantly for those who had recovered, while the scores remained the same for those who were still anorexic. Again, reanalysing the data of Hsu (1978), of the $18(36 \%)$ who reported some depressive feelings, six could be diagnosed on retrospective analysis of the case summaries as follows: schizoaffective disorder (1), obsessive compulsive disorder (1), bipolar disorder (1), social phobia (1), and major depression (2). Apart from the one patient with the bipolar disorder none of the other patients had any significant anorexic or bulimic symptoms. Of the remaining 12 patients with depressive features not diagnosable as major depression, five qualified for a diagnosis of bulimia nervosa at normal weight, three for bulimic anorexia nervosa, three for restrictive anorexia nervosa, and only one was free from any eating disorder symptoms. Even allowing for the limitations of a retrospective analysis, the evidence is compelling that $(l)$ minor depressive features occur predominantly in those with a chronic eating disorder, and (2) for those who have recovered from anorexia nervosa, normal weight bulimia nervosa (not major depression) is the most common diagnosis. Strober \& Katz (1987), addressing the issue of the nosological relationship between affective and eating disorders, suggested that depression may represent a final common pathway for many chronic psychiatric disorders not genetically related to each other, such as alcoholism, antisocial personality disorder, and schizophrenia. The evidence from the intermediate outcome studies certainly does not support the 
view that anorexia nervosa in time changes into major depression. Finally, the long-term course of anorexia nervosa in Theander's study (1985) does not at all resemble that of an affective illness (Keller, 1985), a point we will come to presently.

\section{LONG-TERM OUTCOME OF ANOREXIA NERVOSA}

Russell (1970) originally suggested that a follow-up duration of at least four years is probably necessary for the anorexic illness to run its full course. The recent findings of Theander (1985) and Russell (1987, personal communication) suggest otherwise. The longer the follow-up, the more the patients who have recovered, but also the more who have died. This is well illustrated by Theander's study. At five years after onset of illness $18 \%$ had a poor outcome and $8 \%$ had died. At 33 years, the figures were $6 \%$ and $18 \%$ respectively. Thus, those that remained ill at five years may run a significant risk of succumbing to the illness in the long run. Of those that have recovered, about onethird do so by three, six, and 12 years after onset respectively. Recovery after 12 years is rare. The most common causes of death are starvation (12/17) and suicide (5/17). Two-thirds (11/17, or $12 \%$ overall) of the deaths in the Swedish study occurred within the first seven years of onset of illness. The mortality rate within a similar time period after onset of illness in the recent studies (see above) are lower (0-5\%), and perhaps attributable to better treatment (Crisp, 1981). However, none of the studies were designed to test treatment effects.

\section{ANOREXIA NERVOSA VOMITING SUBGROUP AND BULIMIA NERVOSA : ONE ILLNESS OR TWO?}

The DSM-III-R provides no weight criteria for bulimia nervosa, nor did Russell (1979), who originally proposed the term. A patient at $85 \%$ average weight having lost, say, $20 \%$ of weight, and bingeing and vomiting three times a week will, according to the DSM-III-R, be given either a diagnosis of both anorexia nervosa and bulimia nervosa or of bulimia nervosa alone. This is unsatisfactory for two reasons.

(1). There is good evidence from the outcome studies reviewed above that the anorexia nervosa vomiting subgroup runs true-to-form, and available evidence suggests that normal weight bulimia nervosa does the same (Swift et al. 1987).

(2). The treatment principles of the two disorders are different; weight gain is usually mandatory for the former if only to prevent death, but not for the latter. Since a diagnosis usually carries some treatment implications, to give the same diagnosis to two disorders that require different treatment breeds ambiguity. Therefore, I suggest that the division of $(I)$ anorexia nervosa, sub-divided into the restricting (or abstaining) subgroup and vomiting (or bulimic) subgroup, and (2) bulimia nervosa at normal weight should be retained.

\section{CONCLUSION}

The uniformity in the findings of the intermediate term outcome studies confirm the earlier contention that outcome in a given series is determined largely by case selection factors and followup methodology. The long-term outcome studies indicate that duration of follow-up is the third crucial factor. All the outcome studies show that anorexia nervosa does not 'change' into major depression, and that the two subgroups (restrictive versus vomiting) seem to each run their own distinctive course. Although the standardized mortality ratio is unknown, the mortality of anorexia nervosa appears to be substantial; whether vigorous treatment by weight restoration and psychotherapy may have prevented some early deaths is unclear. Clearly, it is time to move on from the intermediate-term outcome studies to the long-term outcome studies. Needless to say, only a prospective study may provide more definitive answers to the issues discussed in this paper but the ethical and financial difficulties will be considerable.

This study was supported in part by NIMH grant MH39118.

L. K. G. HSU 


\section{REFERENCES}

Burns, T. \& Crisp, A. H. (1984). Outcome of anorexia nervosa in males. British Journal of Psychiatry 145, 319-325.

Cantwell, D. P., Sturzenberger, S., Burroughs, J., Salkin, B. \& Green J. K. (1977). Anorexia nervosa: an affective disorder? Archives of General Psychiatry 34, 1087-1093.

Crisp, A. H. (1977). The differential diagnosis of anorexia nervosa. Proceedings of the Royal Society of Medicine 70, 686-690.

Crisp, A. H. (1981). Therapeutic outcome in anorexia nervosa Canadian Journal of Psychiatry 26, 232-235.

Cutting J. (1986). Outcome of schizophrenia: Overview. In Contemporary Issues in Schizophrenia (ed. A. Kerr \& P. Snaith), pp. 433-440. Gaskell, The Royal College of Psychiatrists: London.

Feighner, J. P., Robins, E., Guze, S. B., Woodruff, R., Winokur, G. \& Munoz, R. (1972). Diagnostic criteria for use in psychiatric research. Archives of General Psychiatry 26, 57-63.

Hall, A., Slim, E., Hawker, F. \& Salmond, C. (1984). Anorexia nervosa: long-term outcome in 50 female patients. British Journal of Psychiatry 145, 407-413.

Hsu, L. K. G. (1978). Anorexia nervosa-a prognostic study. Unpublished dissertation for the degree of M.D., University of Hong Kong.

Hsu, L. K. G. (1980). Outcome of anorexia nervosa. A review of the literature (1954-1978). Archives of General Psychiatry 37, 1041-1046.

Hsu, L. K. G. \& Crisp, A. H. (1980). The Crown-Crisp experiential profile in anorexia nervosa. British Journal of Psychiatry 136, $567-573$.

Hsu, L. K. G., Crisp, A. H. \& Harding, B. (1979). Outcome of anorexia nervosa. Lancet $\mathrm{i}, 61-65$.

Keller, M. B. (1985). Chronic and recurrent affective disorders: Incidence, course, and influencing factors. In Chronic Treatments in Neuropsychiatry, (ed. D. Kemali \& G. Racagni), pp. 111-120. Raven Press: New York.

Leff, J. \& Vaughn, C. (1980). The interaction of life events and relatives' expressed emotion in schizophrenia and depressive neurosis. British Journal of Psychiatry 136, 145-153.
Morgan, H. G. \& Russell, G. F. M. (1975). Value of family background and clinical features as predictors of long-term outcome in anorexia nervosa: Four year follow-up study of 41 patients. Psychological Medicme 5, 355-371.

Morgan, H. G., Purgold, J. \& Welbourne, J. (1983). Management and outcome in anorexia nervosa: $A$ standardized prognostic study. British Journal of Psychiatry 143, 282-297.

Russell, G. F. M. (1970). Anorexia nervosa: Its identity as an illness and its treatment. In Modern Trends in Psychological Medicine, 2. (ed. J. H. Price). Butterworths: London.

Russell, G. F. M. (1979). Bulimia nervosa: an ominous variant of anorexia nervosa. Psychological Medicine 9, 429-448.

Steinhausen, H. C. \& Glanville, K. (1983). Follow-up studies of anorexia nervosa: a review of research findings. Psychological Medicine 13, 239-249.

Strober, M. \& Katz. J. L. (1987). Do eating disorders and affective disorders share a common etiology? International Journal of Eating Disorders 6, 171-180.

Sturzenberger, S., Cantwell, D. P., Burroughs, J., Salkin, B. \& Green, J. K. (1977). A follow-up study of adolescent psychiatric inpatients with anorexia nervosa. Journal of the American Academy of Child Psychiatry 16, 703-715

Swift, W. J., Ritholz, M., Kalin, N. H. \& Kaslow, N. (1987). A follow-up study of thirty hospitalızed bulimics. Psychosomatic Medicine 49, 45-55.

Szmukler, G. I., Eisler, I., Russell, G. F. M. \& Dare, C. (1985). Anorexia nervosa, parental 'expressed emotion' and dropping out of treatment. British Journal of Psychiatry 147, 265-271.

Theander, S. (1970). Anorexia nervosa: a psychiatric investigation of 94 female patients. Acta Psychiatric Scandinavia Supplement, 214.

Theander, S. (1985). Outcome and prognosis in anorexia nervosa and bulimia: some results of previous investigations, compared with those of a swedish long-term study. Journal of Psychiatric Research 19, 493-508. 